\title{
Diabetic microangiopathy in Type 1 (insulin-dependent) diabetic patients after successful pancreatic and kidney or solitary kidney transplantation
}

\author{
D. Abendroth ${ }^{1}$, J. Schmand ${ }^{1}$, R. Landgraf ${ }^{2}$, W.-D. Ilher ${ }^{1}$ and W. Land ${ }^{1}$ \\ ${ }^{1}$ Division of Transplant Surgery, Klinikum Grosshadern and ${ }^{2}$ Medical Clinic "Innenstadt", University of Munich, FRG
}

Summary. To evaluate the beneficial effect of pancreatic grafting on peripheral microcirculation and long-term clinical outcome, we compared data of 28 Type 1 (insulindependent) diabetic patients either given a pancreatic and kidney graft simultaneously or given a solitary kidney graft $(n=17)$. Peripheral microcirculation was estimated by transcutaneous oxygen pressure measurement (including reoxygenation potential after blood flow occlusion) and erythrocyte flow / velocity by a non-contact laser speckle method. All the measured parameters showed significant differences between diabetic and control subjects in the mean follow-up time of 49 (simultaneous pancreas and kidney transplantation) and 43 (solitary kidney transplantation) months. The data from patients after simultaneous pancreas and kidney transplantation revealed an improvement of transcutaneous oxygen pressure measurement (rise from $46 \pm 2 \mathrm{~mm} \mathrm{Hg}$ to $63 \pm 3$ $\mathrm{mmHg}$ ), reoxygenation time (fall from $224 \pm 12 \mathrm{~s}$ to $114 \pm$ $6 \mathrm{~s}$ ) and laser speckle measurement (rise from $4.2 \pm 1.7$ to $5.6 \pm 1.8$ relative units). The control group with solitary kidney transplantation did not show a positive evaluation. Data from patients after simultaneous pancreas and kidney transplantation revealed an improvement in transcutaneous oxygen pressure measurement, reoxygenation time and laser speckle measurement whereas the control group with solitary kidney transplantation did not show a positive evaluation. Improved microcirculation was more pronounced in patients with better microvascular preconditions. The results confirm that diabetic microangiopathy is positively influenced by pancreatic transplantation.

Key Words: Simultaneous pancreas and kidneytransplantation - Reactive hyperaemia response - Transcutaneous oxygen pressure measurement - Laser speckle measurement.

\section{Introduction}

So far, successful pancreatic transplantation is the only effective way to correct dysfunctioning carbohydrate metabolism in Type 1 (insulin-dependent) diabetic patients. The main purposes of pancreas transplantation are to prevent, halt or reverse secondary complications. Evidence suggesting a relationship between achieved normoglycaemia and a potential beneficial influence on these complications must still be proven (Sutherland 1990). Peripheral vascular insufficiency is the most frequent complication in patients with Type 1 diabetes.

In this study we investigated the effect of pancreatic transplantation on peripheral microcirculation and longterm clinical outcome. We compared data from Type 1 diabetic patients either given a pancreatic and kidney graft simultaneously (SPKT) or given a solitary kidney (SKT).

\section{Subjects and Methods}

Patients: Twenty-eight Type 1 diabetic patients (group I) were investigated prior to and up to 60 months after successful SPKT. Group II (control) comprised 17 Type 1 diabetic patients with SKT. Further demographic data are shown in Table 1.

Both groups suffered from late secondary complications and received treatment with different immunosuppressive protocols as recently published (Land 1987; Landgraf 1989).

Thirty-one healthy subjects served as a control group for the laset speckle-method and 86 for transcutaneous oxygen pressure measurement and reoxygenation-time measurements.

The peripheral microcirculation was measured using two non-invasive methods: transcutaneous oxygen pressure measurement (Kontron, Eching b.München/FRG) and erythrocyte flow by laser speckle method (Gerätebau Odenwald, Grasellenbach/FRG) similar to the doppler flow technique (Abendroth 1987). 
Transcutaneous oxygen pressure measurement $\left(t c p \mathrm{O}_{2}\right)$ : The $\mathrm{tcpO}_{2}$ registered by the skin surface electrode is a measure of hyperaemic flow through nutritional intradermal skin capillaries and reoxygenation potential after total blood flow occlusion. The skin is locally heated up to $440 \mathrm{C}$ so that maximum intra- and subdermal vessel dilatation is achieved (Sunder-Plassmann 1986).

Table 1. Clinical data of the patients prior to panereas transplantation

\begin{tabular}{|c|c|c|}
\hline & $\begin{array}{l}\text { Group } 1 \\
n=28\end{array}$ & $\begin{array}{l}\text { Group } 2 \\
\mathrm{n}=17\end{array}$ \\
\hline Age (years) & $34 \pm 1$ & $38 \pm 1$ \\
\hline $\begin{array}{l}\text { fermale } \\
\text { male }\end{array}$ & $\begin{array}{l}14 \\
14\end{array}$ & $\begin{array}{r}5 \\
12\end{array}$ \\
\hline $\begin{array}{l}\text { Duration of } \\
\text { diabetes (years) }\end{array}$ & $20 \pm 1$ & $26 \pm 1$ \\
\hline $\begin{array}{r}\text { Hypertension } \\
\text { yes } \\
\text { no }\end{array}$ & $\begin{array}{r}24 \\
4\end{array}$ & $\begin{array}{r}15 \\
2\end{array}$ \\
\hline $\begin{array}{l}\text { Retinopathy } \\
\text { Grade II } \\
\text { Grade III } \\
\text { Blind }\end{array}$ & $\begin{array}{r}8 \\
20 \\
3\end{array}$ & $\begin{array}{r}5 \\
12 \\
2\end{array}$ \\
\hline $\begin{array}{l}\text { Neuropathy } \\
\text { mild } \\
\text { moderate } \\
\text { severe }\end{array}$ & $\begin{array}{l}4 \\
21 \\
3\end{array}$ & $\begin{array}{r}3 \\
12 \\
2\end{array}$ \\
\hline Dialysis (months) & $20 \pm 14$ & $39 \pm 1$ \\
\hline
\end{tabular}

Basal values of tcpO 2 were evaluated after establishing steady-state conditions, which were usually achieved 10-15 min after attaching the sensor to the skin. Steady-state conditions were defined as tcpO 2 -variation less than $\pm 2 \mathrm{~mm} \mathrm{Hg}$ for at least $5 \mathrm{~min}$.

Reactive hyperaemia response (reoxygenation-time). This cuff-occlusion test is a dynamic evaluation to diagnose vascular diseases related primarily to the cutaneous circulation. A standardized arm-cuff placed around the ankle was inflated to a supra-systolic value and suddenly released after $3 \mathrm{~min}$ of occlusion. In the presence of microangiopathy the delay in re-establishment of the control $\mathrm{pO}_{2}$ is characteristic and any therapeutic effect can be registered as a decrease in delay (Franzeck 1982).

Laser-speckle: non-contact detection of skin-microcirculation. A Helium-Neon-laser beam penetrates the skin to a mean depth 2 of $0.5 \mathrm{~mm}$. Thus, the capillaries are within the range of the laser light, skin blood flow / blood velocity can be measured on a level above the thermoregulatory arterio-venous shunts. This is carried out by utilizing the dynamic laser-speckle-effect (Dainty 1975). In order to separate several possible disturbances - e.g. unconscious body movements, the scattered light is regarded as a superposition of two dynamic speckle pattems (Ruth 1987).

The method is easy to use, side-effect free and as a non-invasive-method it does not disturb the microcirculation. So we can define a "relative blood flow parameter", however a quantitative analysis of our data is not possible with this method.

Examinations. The skin microcirculation was studied in the fore-foot area (os cuboid $\mathrm{I}$ ). The subjects were in a comfortable supine position and all measurements were done on the dorsum of the foot. All examinations were performed in a temperature-controlled room at $24^{\circ} \mathrm{C} \pm 1{ }^{\circ} \mathrm{C}$ under standard conditions.
Statistical analysis. The results are given as mean \pm 1 SD. For estimating statistically significant differences between both groups the Wil. coxon test of paired samples was used. A p-level of $<0.05$ was considered significant.

\section{Results}

The mean follow-up period was 49 months (range 12 to 63 months) in group I and 43 months (range 11 to 61 months) in group II.

The 3-year survival rate in group I (group II) for patients is $100 \%(60 \%)$ for pancreas $77 \%$ and for the kidney $74 \%$ (24\%).

Group I-patient tcpO2 values increased significantly from $46 \pm 2 \mathrm{mmHg}$ to $63 \pm 3 \mathrm{mmHg}$ in the third year post-transplant (Figure 1). The normal values of 86 healthy volunteers for tcpO2 are $67 \pm 7 \mathrm{mmHg}$.

At the same time post-occlusive reactive hyperaemia response (reoxygenation-time) decreased from $224 \pm 12 \mathrm{~s}$ to $114 \pm 6 \mathrm{~s}$ (Fig. 2). Normal values are $79 \pm 1.5 \mathrm{~s}$

The corresponding values for diabetic patients with solitary kidney transplantation ( $\mathrm{tcpO} 244 \pm 3$ to $41 \pm 2$ $\mathrm{mmHg} ; 219 \pm 7 \mathrm{~s}$ to $244 \pm 10 \mathrm{~s}$ ) did not show any improvement.

Laser speckle signal showed also a better "relative blood flow" in patients after SPKT (36 months) as compared with those directly prior to transplantation (Fig. 3). Normal values for the "relative blood flow" of 31 healthy volunteers are $6,1 \pm 1,9$ relative units.

Using both methods we found in all three parameters significant differences between diabetic patients after SPKT and solitary KT as well as normal control subjects. On descriminant analysis performed for reoxygenation time as a "dynamic test", we found that this is a more reliable parameter to discriminate between diabetic and control subjects than baseline values.

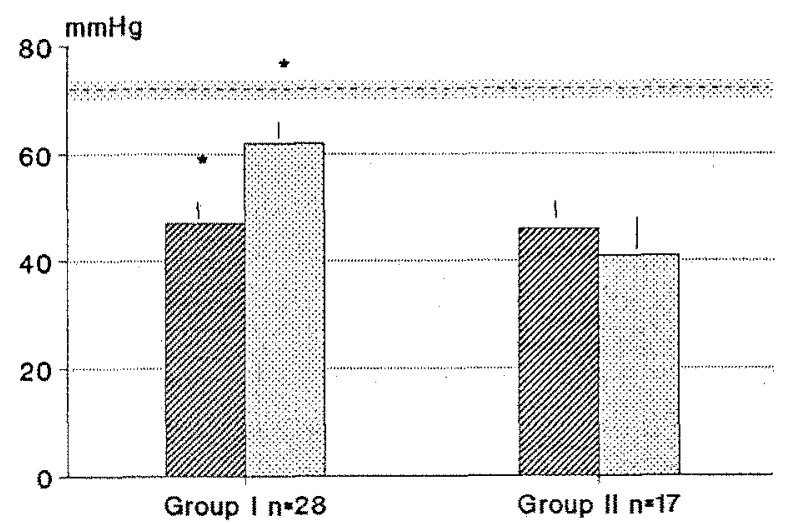

Fig. 1: Transcutaneous oxygen pressure measurement $\left(\mathrm{tcpO}_{2}\right)$ prior to (striped) and 36 months after (dotted) successful pancreas and kidney transplantation. (Controls $n=86, *=p<0.001$ )

In the clinical course amputation was more frequent in group II than in group I ( $1 \mathrm{x}$ thigh, $3 \mathrm{x}$ lower 1 eg, $5 \mathrm{x}$ toes in group II; $1 \times$ lower leg, $4 \times$ toes in group I). 


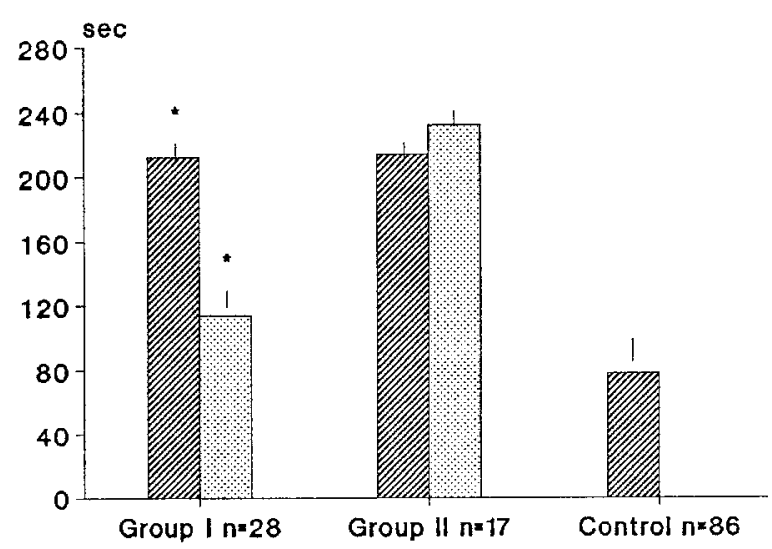

Fig. 2: Reoxygenation time showing a marked improvement only in the simultaneous pancreas and kidney transplantation (SPKT)-group I (pre-transplantation = striped bars; post-transplantation ( 36 months) $=$ dotted bars).

Blindness occurred twice in group II and the insulin requirement was $+27 \%$ in group $\Pi$.

Rel.U.

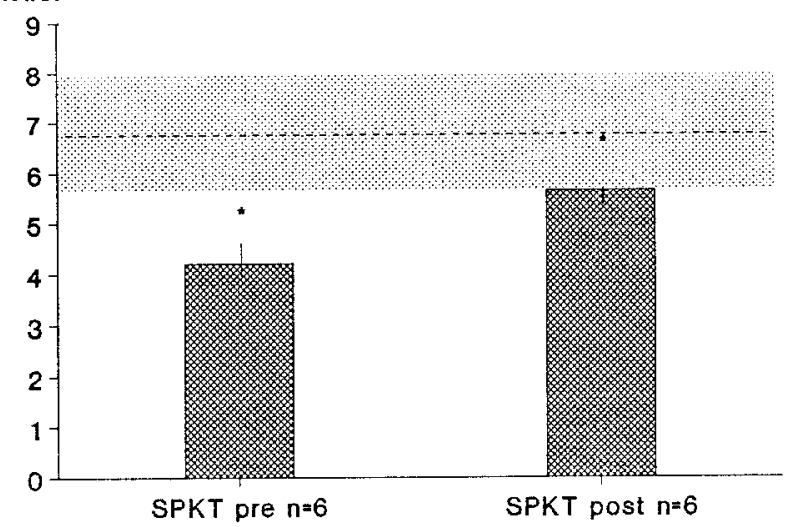

Fig. 3: Laser-Speckle-values (in relative units) are showing an increase after simultaneous pancreas and kidney transplantation ( 36 months) (S.E.M. = -; controls $\mathbf{n}=31=--;{ }^{*} \mathrm{p}=<0.05$ ).

\section{Discussion}

These results demonstrate a diminished transcutaneous oxygen pressure and an impaired regulatory response of skin microcirculation associated with Type 1 diabetes mellitus. The reoxygenation-time during post-occlusive reactive hyperaemia was found to be prolonged in both groups, and the relative blood flow parameter was decreased. Findings in patients with long-standing Type 1 diabetes with severe late complications showed a significant impairment of all microvascular parameters pretransplantation. After successful SPKT most values compared to the healthy control subjects were still impaired but significantly better with tendency to (near) normal values.
$\mathrm{TcpO}_{2}$-values vary with the site of the body where the measurement is being performed. Thus, an exact standardization of the site of the measurement is very important for a reproducible measurement of tcpO 2 . We have chosen the fore-foot region and not the fore-arm or fingers because the latter are usually less affected even in patients with severe peripheral arterial occlusive disease. The study was carried out at an electrode temperature of $44{ }^{\circ} \mathrm{C}$ for several reasons: firstly to suppress any periodic microcirculatory changes by maximal hyperaemia and secondly neurocirculatory phenomena affecting the periodic changes of peripheral blood flow at lower temperatures can be excluded (Sunder-Plassmann 1986).

According to Franzeck (1982) the post-occlusive reactive hyperaemia response (reoxygenation time) monitored by $\mathrm{tcpO}_{2}$, during recovery from peripheral arterial occlusion was evaluated. This functional parameter appeared to be more sensitive in discriminating between diabetic patients and control subjects as well as between patients after SPKT or SKT. The reactive hyperaemia response after an arterial occlusion is supposed to be influenced by vasodilating metabolites produced by the ischaemia during occlusion (>1 min). The prolonged reoxygenation time found in patients prior topancreatic transplantation may be explained by structural changes and/or high vascular tone in the precapillary arterioles, hindering relaxation of the smooth muscle cells in the vascular wall.

Normalization indicates an improved ability to relax smooth muscle in these patients. These findings are supported by Beggs et al. (Beggs 1990) describing signs of nerve regeneration and repair following pancreas transplantation. The still partially impaired values might be due to hypertension still existing in these patients or to beta-blocking drugs.

The lower $\mathrm{tcpO}_{2}$-values observed in Type 1 diabetic patients were influenced by the presence of microvascular late complications of the disease. These results may indicate the occurrence of an early functional abnormality concerning tcpO2 2 by microcirculatory disorders.

Metabolic factors, however, are important in determining shunt flow: poor diabetes control is associated with increased blood flow and recent microcirculatory studies indicate that this is essentially due to a rise in shunt flow, which effectively bypasses capillary nutrient circulation (Tooke 1985).

$\mathrm{TcpO}_{2}$, although decreased, was still sufficient for appropiate oxygenation of the cutaneous layers not leading to manifest lesions. It is unknown whether the changes of tcpO 2 and other parameters are merely due to microcirculatory disorders precipitated by metabolic alterations - e.g. hyperglycaemia, or hyperosmolarity resulting in increased blood viscosity and decreased erythrocyte deformability.

It has been shown by studies evaluating maximal cutaneous flow by laser Doppler techniques, that there is a significantly lower flow velocity in diabetic patients (12). 
The most likely explanation for flow abnormalities is the peripheral autonomic neuropathy which leads to a widely dilated vascular bed.

In conclusion patients after solitary kidney transplantation showed a marked impairment of skin microcirculation compared to patients after simultaneous pancreas and kidney transplantation. This may indicate that normoglycemia and not the kidney function is responsible for the improvement of microvascular reactivity.

Moreover most of our patients have probably passed the stage, in which microangiopathy can be completely reversed by normalization of glucose metabolism. Pancreas grafting probably has to be performed much earlier in the course of diabetes.

\section{References}

Abendroth D, Sunder-Plassmann L, Land W, Landgraf R (1987) Changes of diabetic microangiopathy after pancreas transplantation. Transpl.Proc. 19: 3886-3887.

Beggs Л, Johnson PC, Olafsen AG, et al (1990) Signs of nerve regeneration and repair following pancreas transplantation in an insulin-dependent diabetic with neuropathy. Clin.Transplantation 4: 133-141.

Dainty J.C. (Ed.) (1975) Laser speckle and related phenomena. Springer Berlin Heidelberg New York

Franzeck UK, Talke P, Fronek A, et al (1982) Transcutaneous $\mathrm{pO}_{2}$ measurements in health and peripheral arterial occlusive disease. Surgery 91 (2): 156

Land W, Landgraf R, Mlner WD, et al (1987) Clinical pancreas transplantation. The world experience. Transpl.Proc. 19 (Suppl.4): 75

Landgraf R, Nusser J, Scheuer R, et al (1989): Metabolic Control and effect on secondary complications of diabetes mellitus by pancreatic transplantation. Baillier's Clinical Gastroenterology. Vol. 3: No 4, 865-876.

Landgraf R, Nusser J, Müller W, et al (1989) Fate of late complications in Type I diabetic patients after successful pancreas-kidney transplantation. Diabetes 38 (Suppl. 1): 33-37

Ruth B, (1987) Superposition of two dynamic speckle patterns - an application to non-contact blood flow-measurements. J.Mod.Optics, Vol. 34: [No 2] 257-273

Sunder-Plassmann L, Abendroth E, Becker HM (1986) In: Mahler F, Meßmer K, Mammerson F (eds): Techniques in clinical capillary microscopy. Karger Basel 124

Sutherland DER (1990) Indications for pancreas transplantation. A commentary. Clin.Transplantation 4: 242-246

Tooke JE, Lins PE, Oestergren J, et al (1985) Skin microvascular autoregulatory responses in type I diabetes. The influences of time and control. Int.J. Microcirc.Clin.Exp. 4: 249-256

Tooke JE (1986) Microvascular haemodynamics in diabetes mellitus. Clin. Sci. 70: 119-125.
Priv.-Doz. Dr. D. Abendroth

Division of Transplant Surgery

Klinikum Grosshadern, University of Munich

Marchioninistr.15

8000 München 70/FRG 